\title{
Within-breed and multi-breed GWAS on imputed whole-genome sequence variants reveal candidate mutations affecting milk protein composition in dairy cattle
}

\author{
Marie-Pierre Sanchez ${ }^{1 *}$, Armelle Govignon-Gion ${ }^{1,2}$, Pascal Croiseau', Sébastien Fritz ${ }^{1,3}$, Chris Hozé ${ }^{1,3}$, \\ Guy Miranda ${ }^{1}$, Patrice Martin' ${ }^{1}$, Anne Barbat-Leterrier ${ }^{1}$, Rabia Letaïef ${ }^{1}$, Dominique Rocha ${ }^{1}$, Mickaël Brochard², \\ Mekki Boussaha ${ }^{1}$ and Didier Boichard ${ }^{1}$
}

\begin{abstract}
Background: Genome-wide association studies (GWAS) were performed at the sequence level to identify candidate mutations that affect the expression of six major milk proteins in Montbéliarde (MON), Normande (NOR), and Holstein $(\mathrm{HOL})$ dairy cattle. Whey protein (a-lactalbumin and $\beta$-lactoglobulin) and casein (as1, as2, $\beta$, and $\mathrm{k}$ ) contents were estimated by mid-infrared (MIR) spectrometry, with medium to high accuracy $\left(0.59 \leq R^{2} \leq 0.92\right)$, for 848,068 test-day milk samples from 156,660 cows in the first three lactations. Milk composition was evaluated as average test-day measurements adjusted for environmental effects. Next, we genotyped a subset of 8080 cows (2967 MON, 2737 NOR, and $2306 \mathrm{HOL}$ ) with the BovineSNP50 Beadchip. For each breed, genotypes were first imputed to high-density (HD) using HD single nucleotide polymorphisms (SNPs) genotypes of $522 \mathrm{MON}, 546 \mathrm{NOR}$, and $776 \mathrm{HOL}$ bulls. The resulting HD SNP genotypes were subsequently imputed to the sequence level using 27 million high-quality sequence variants selected from Run4 of the 1000 Bull Genomes consortium (1147 bulls). Within-breed, multi-breed, and conditional GWAS were performed.
\end{abstract}

Results: Thirty-four distinct genomic regions were identified. Three regions on chromosomes 6, 11, and 20 had very significant effects on milk composition and were shared across the three breeds. Other significant effects, which partially overlapped across breeds, were found on almost all the autosomes. Multi-breed analyses provided a larger number of significant genomic regions with smaller confidence intervals than within-breed analyses. Combinations of within-breed, multi-breed, and conditional analyses led to the identification of putative causative variants in several candidate genes that presented significant protein-protein interactions enrichment, including those with previously described effects on milk composition (SLC37A1, MGST1, ABCG2, CSN1S1, CSN2, CSN1S2, CSN3, PAEP, DGAT1, AGPAT6) and those with effects reported for the first time here (ALPL, ANKH, PICALM).

Conclusions: GWAS applied to fine-scale phenotypes, multiple breeds, and whole-genome sequences seems to be effective to identify candidate gene variants. However, although we identified functional links between some candidate genes and milk phenotypes, the causality between candidate variants and milk protein composition remains to be demonstrated. Nevertheless, the identification of potential causative mutations that underlie milk protein composition may have immediate applications for improvements in cheese-making.

\footnotetext{
*Correspondence: marie-pierre.sanchez@inra.fr

${ }^{1}$ GABI, INRA, AgroParisTech, Université Paris Saclay, 78350 Jouy-en-Josas, France

Full list of author information is available at the end of the article
} 


\section{Background}

In cattle, milk protein composition is mostly influenced by genetic factors [1-4] and is of interest because it determines cheese-making properties [5]. Bovine milk protein composition can be predicted at a large scale by analyzing mid-infrared (MIR) spectra, which is routinely performed $[6,7]$. Combined with cow genotyping, this technique may open avenues to investigate the genomic regions that influence milk protein composition. In a previous genome-wide association study (GWAS) based on the bovine $50 \mathrm{~K}$ single nucleotide polymorphism (SNP) array, we highlighted numerous genomic regions with very significant effects on milk protein composition in the three main breeds of French dairy cattle: Holstein (HOL), Montbéliarde (MON), and Normande (NOR) [8]. However, because the $50 \mathrm{~K}$ SNP array contains only a small fraction of the total number of genomic variants, we were not able to directly pinpoint candidate mutations.

In Run4 of the 1000 bull genome reference population, a database containing more than 56 million SNPs and small insertions/deletions (InDel) was constructed by analyzing whole-genome sequences (WGS) from 1147 bulls representing 27 different breeds, including 288 HOL, $28 \mathrm{MON}$ and 24 NOR bulls. These data can then be used to impute WGS from experimentally or routinely obtained $50 \mathrm{~K}$ SNP genotypes [9]. In this way, imputed WGS can be obtained for a large number of animals and in particular, those with phenotypes.

Since WGS contain almost all the genomic variants, they should contain the causal mutations for a given trait and, thus they provide a much higher GWAS resolution. However, due to the long-range linkage disequilibrium that exists within dairy cattle breeds, the resolution of withinbreed GWAS is often limited. For causal mutations that are shared among breeds, a multi-breed model can be used to refine regions that harbour quantitative trait loci (QTL). This approach takes advantage of the historical recombination events that have occurred in each breed, resulting in linkage disequilibrium over shorter distances and better resolution [10].

Here, we report the results of a GWAS at the sequence level for six major milk protein contents, namely $\alpha$-lactalbumin and $\beta$-lactoglobulin and $\alpha \mathrm{s} 1, \alpha \mathrm{s} 2, \beta$, and $\mathrm{k}$ caseins from HOL, MON, and NOR cows. The results of within-breed, multi-breed, and conditional analyses, that fit the most significant variant in addition to other tested variants, are examined together in order to pinpoint potential candidate variants in each genomic region.

\section{Methods}

\section{Animals, phenotypes, and genotypes}

For this study, we did not perform any animal experiment, thus no ethical approval was required. Details on the animals and milk analyses are in Sanchez et al. [8]. Briefly, MIR spectra were obtained for 848,068 milk samples from 156,660 cows of the three main French dairy breeds: Montbéliarde (MON), Normande (NOR), and Holstein (HOL). These spectra were used to predict milk protein content (PC) and milk protein composition with the equations derived as described by Ferrand et al. [7]. More details about the method and the calibration population used are in Sanchez et al. [4]. The contents of the six main milk proteins $\left(\alpha_{\mathrm{s} 1}-\mathrm{CN}, \alpha_{\mathrm{s} 2}-\mathrm{CN}, \beta-\mathrm{CN}, \kappa-\mathrm{CN}\right.$, $\alpha$-LA, and $\beta$-LG) were predicted in $\mathrm{g} / 100 \mathrm{~g}$ protein. Total casein content and total whey protein content were also analyzed ( $\Sigma$-CN and $\Sigma$-WP, respectively). In order to adjust phenotypes for non-genetic effects, a withinbreed mixed model was applied to test-day data using the GENEKIT software [11]. This single-trait repeatability model included genetic, permanent environmental, and residual random effects, as well as herd $\times$ test-day, parity $\times$ stage of lactation, year $\times$ month of calving, and spectrometer $\times$ test month fixed effects. We applied this model to data from the first two lactations that included at least three test-day records across lactations during the study period. Then, test-day data were corrected for all non-genetic effects included in the model and averaged per cow. Thus, for each trait and each cow, a single phenotype was defined and subsequently used in GWAS analyses. In total, 293,780, 58,594, and 72,973 test-day records were analyzed, which corresponded to $44,959 \mathrm{MON}, 12,428 \mathrm{NOR}$, and 14,530 HOL cows, i.e. an average of $6.5,4.7$, and 5.0 test-day records per cow, respectively.

Among these cows, 8010 were genotyped with the Illumina BovineSNP50 BeadChip (Illumina Inc., San Diego). We applied the following quality control filters: the individual call rate had to be higher than 95\%, the SNP call rate higher than $90 \%$, the minor allele frequency (MAF) higher than 5\%, and genotype frequencies had to be in Hardy-Weinberg equilibrium with $P>10^{-4}$. The final dataset included between 37,332 and 41,028 SNPs (Table 1), depending on the within-breed or multi-breed population considered, for 7907 cows (3032 MON, 2659 NOR, and 2216 HOL) with phenotypes.

\section{Imputation to whole-genome sequences}

The $50 \mathrm{~K}$ SNP genotypes of the 7907 cows were imputed to whole-genome sequence (WGS) using FImpute software, which accurately and quickly analyzes large datasets [12]. A two-step approach was applied in order to improve the accuracy of results: from 50 to $777 \mathrm{~K}$ highdensity (HD) SNPs, and then, from imputed HD SNPs to WGS [13]. All imputations were performed separately for each breed using either a breed-specific (from $50 \mathrm{~K}$ to HD SNPs) or a multi-breed (from HD SNPs to WGS) 
Table 1 Features of the Montbéliarde (MON), Normande (NOR), Holstein (HOL), and multi-breed populations

\begin{tabular}{|c|c|c|c|c|}
\hline Number of & MON & NOR & $\mathrm{HOL}$ & Multi-breed \\
\hline Phenotyped cows & 44,959 & 12,428 & 14,530 & 71,917 \\
\hline $\begin{array}{l}\text { Total test-day } \\
\text { records }\end{array}$ & 293,780 & 58,594 & 72,973 & 425,347 \\
\hline $\begin{array}{l}\text { Test-day records per } \\
\text { cow }\end{array}$ & 6.5 & 4.7 & 5 & 5.9 \\
\hline Genotyped cows & 3032 & 2659 & 2216 & 7907 \\
\hline $\begin{array}{l}\text { Polymorphic } 50 \mathrm{~K} \\
\text { SNPs }\end{array}$ & 37,332 & 37,690 & 39,158 & 41,028 \\
\hline $\begin{array}{l}\text { Polymorphic HD } \\
\text { SNPs }\end{array}$ & 548,185 & 549,359 & 553,712 & 586,749 \\
\hline $\begin{array}{l}\text { Polymorphic } \\
\text { sequence variants }\end{array}$ & $15,957,336$ & $14,809,860$ & $15,116,501$ & $18,366,748$ \\
\hline $\begin{array}{l}\text { Sequence variants } \\
\quad(M A F \geq 2 \%)\end{array}$ & $11,755,172$ & $11,445,432$ & $11,592,432$ & $13,534,013$ \\
\hline
\end{tabular}

reference panel depending on the targeted density [14]. In each MON, NOR and HOL breed, imputations to the HD SNP level were performed using a within-breed reference population that included respectively $522 \mathrm{MON}$, 546 NOR, and $776 \mathrm{HOL}$ bulls that had been genotyped with the Illumina BovineHD BeadChip (Illumina Inc., San Diego, CA). Around 550,000 SNPs were retained in each breed after removing SNPs that failed in the quality control filters, as described above for the $50 \mathrm{~K}$ (Table 1). WGS variants were imputed from HD SNP genotypes using WGS variants of the 1147 bulls from Run 4 of the 1000 Bull Genomes consortium; these bulls represent 27 cattle breeds (see Additional file 1: Table S1), with 288 HOL, $28 \mathrm{MON}$, and $24 \mathrm{NOR}$ individuals [9]. The protocol used was defined in the "1000 bull genomes" consortium [9]. Whole-genomes of all individuals were used for $2 \times 100$ bp paired-end sequencing using Illumina sequencing-by-synthesis technology and sequence reads were further filtered for quality and subsequently aligned to the UMD3.1 reference sequence, as previously described $[9,15]$. Small genomic variations (SNPs and InDel) were detected using SAMtools 0.0.18 [16]. Raw variants were further filtered to produce $27,754,235$ autosomal variants [15]. Filtered variants were subsequently annotated with the Ensembl variant effect predictor (VEP) pipeline v81 [17] and effect of the amino acid changes was predicted using the SIFT tool [18].

Precision of imputation from HD to sequence was assessed by comparing imputed genotypes with those obtained by re-genotyping a subset of the same cows with a custom chip. This additional information was not used in the imputation process. Two datasets were available: (1) a group of 168 Holstein cows that were genotyped with the first version (V1) of the EuroG10k Illumina chip, with 721 additional markers; and (2) a group of 2142 Montbéliarde cows that were genotyped with the fourth version (V4) of the same EuroG10k chip containing 3082 additional SNPs. Only SNPs with good technical quality (call rate $>95 \%$, validation of the clusters by visual inspection, within-breed allelic frequency not significantly different across chip versions) were used. Imputation accuracy was measured by the squared correlation between true and imputed genotypes and by the genotypic and allelic concordance rate.

In order to remove SNPs with the lowest accuracies of imputation, only variants with a MAF higher than 0.02 were retained for further association analyses. Thus, about 11 million variants were included in each withinbreed analysis and around 13 million were included in multi-breed analyses (Table 1).

\section{Whole-genome sequence association analyses}

We performed single-trait association analyses between all the polymorphic variants and the nine measured milk protein composition traits: PC, $\alpha-\mathrm{LA}, \beta-\mathrm{LG}, \alpha_{\mathrm{s} 1}-\mathrm{CN}$, $\alpha_{\mathrm{s} 2}-\mathrm{CN}, \beta-\mathrm{CN}, \mathrm{k}-\mathrm{CN}, \Sigma$-CN, and $\Sigma$-WP (Table 2).

All association analyses were performed using the mlma option of the GCTA software, which applies a mixed linear model that includes the candidate variant [19]:

$$
\mathbf{y}=\mathbf{1} \mu+\mathbf{x b}+\mathbf{u}+\mathbf{e},
$$

where $\mathbf{y}$ is the vector of pre-adjusted phenotypes, averaged per cow; $\mu$ is the overall mean; $b$ is the additive fixed effect of the candidate variant to be tested for association; $\mathbf{x}$ is the vector of imputed genotypes coded as 0,1 , or 2 (number of copies of the second allele); $\mathbf{u} \sim \mathrm{N}\left(\mathbf{0}, \mathbf{G} \sigma_{\mathrm{u}}^{2}\right)$ is the vector of random polygenic effects, with $\mathbf{G}$ the genomic relationship matrix (GRM), calculated by using the HD SNP genotypes [20], and $\sigma_{\mathrm{u}}^{2}$ the polygenic variance, estimated based on the null model $(\mathbf{y}=\mathbf{1} \mu+\mathbf{u}+\mathbf{e})$ and then fixed while testing for the association between each variant and the trait; and $\mathbf{e} \sim \mathrm{N}\left(\mathbf{0}, \mathbf{I} \sigma_{\mathrm{e}}^{2}\right)$ is the vector of random residual effects, with $\mathbf{I}$ the identity matrix and $\sigma_{\mathrm{e}}^{2}$ the residual variance. Within-breed, the number of test-day records did not differ very much across cows, thus, the residual variance was assumed to be constant across cows.

For multi-breed association analyses, Model (2) was applied by adding a fixed breed effect $\mathbf{v}$ to Model (1), with $\mathbf{W}$ as the incidence matrix relating phenotypes to breed effect (three levels), and $\mathbf{x}, \mathbf{b}, \mathbf{u}$, and $\mathbf{e}$ as defined previously:

$$
\mathbf{y}=\mathbf{W} \mathbf{v}+\mathbf{x b}+\mathbf{u}+\mathbf{e}
$$

The Bonferroni correction was applied to the thresholds in order to account for multiple testing. A very stringent 
Table 2 MIR predictions for milk protein composition in Montbéliarde (MON), Normande (NOR), and Holstein (HOL) cows

\begin{tabular}{|c|c|c|c|c|c|c|}
\hline \multirow[t]{2}{*}{ Trait } & & \multicolumn{2}{|c|}{ Accuracy $^{a}$} & \multicolumn{3}{|c|}{ Means \pm standard deviations ${ }^{b}$} \\
\hline & & $\mathrm{R}^{2}$ & $\mathrm{RE}$ & MON & NOR & $\mathrm{HOL}$ \\
\hline PC & Protein content & 1.00 & 0.73 & $3.4 \pm 0.4$ & $3.6 \pm 0.4$ & $3.3 \pm 0.4$ \\
\hline$a-L A$ & a-lactalbumin & 0.59 & 14.4 & $4.07 \pm 0.28$ & $4.16 \pm 0.36$ & $4.27 \pm 0.42$ \\
\hline$\beta-L G$ & $\beta$-lactoglobulin & 0.74 & 11.7 & $8.25 \pm 1.12$ & $7.94 \pm 1.03$ & $8.46 \pm 1.17$ \\
\hline$a_{s 1}-C N$ & $a_{s 1}$-casein & 0.88 & 4.7 & $27.8 \pm 0.55$ & $27.8 \pm 0.68$ & $27.9 \pm 0.69$ \\
\hline$a_{52}-C N$ & $a_{s 2}$-casein & 0.82 & 7.5 & $9.53 \pm 0.30$ & $9.89 \pm 0.33$ & $9.69 \pm 0.39$ \\
\hline$\beta-C N$ & $\beta$-casein & 0.92 & 3.7 & $36.6 \pm 0.88$ & $36.2 \pm 1.2$ & $36.2 \pm 1.2$ \\
\hline $\mathrm{k}-\mathrm{CN}$ & k-casein & 0.80 & 8.4 & $9.75 \pm 0.60$ & $9.87 \pm 0.48$ & $9.43 \pm 0.58$ \\
\hline$\Sigma-\mathrm{CN}$ & Sum of caseins & 0.97 & 2.7 & $83.7 \pm 0.94$ & $83.7 \pm 1.5$ & $83.1 \pm 1.4$ \\
\hline$\Sigma$-WP & Sum of whey proteins & 0.73 & 8.9 & $12.6 \pm 1.1$ & $11.9 \pm 1.2$ & $12.6 \pm 1.3$ \\
\hline
\end{tabular}

a Accuracy of MIR predictions $\left(\mathrm{R}^{2}=\right.$ coefficient of determination and $\mathrm{RE}=$ relative error) estimated by Ferrand et al. [7] for protein composition expressed as $\mathrm{g} / 100 \mathrm{~g}$ milk

b $\mathrm{g} / 100 \mathrm{~g}$ milk for protein content $(\mathrm{PC})$ and $\mathrm{g} / 100 \mathrm{~g}$ protein for other traits

correction was used, which considered all 13 million tests as independent. Therefore, the $5 \%$ genome-wide threshold of significance corresponded to a nominal $P$ value of $3.7 \times 10^{-9}\left(-\log _{10}(P)=8.4\right)$. QTL regions were identified by grouping significant results that were located within the same 2 million base-pair (Mbp) interval in a single genomic region, regardless of the breeds or traits under study. QTL regions were determined by considering positions of variants included in the upper third of the peak. For a given trait in a given breed, when two consecutive QTL regions had overlapping confidence intervals, or when the distance between the limits of the confidence intervals was less than $1 \mathrm{Mbp}$, only the confidence interval that presented the most significant results was retained.

\section{Conditional association analyses}

In the most significant QTL regions, conditional analyses were carried out using the cojo option of GCTA [21] in order to conclude if multiple significant variants in a genomic region were due to LD with the same causal mutation or to the presence of multiple causal mutations. Association analyses were performed by including in the model the most significant variant or the putative causal mutation as a fixed effect and by testing all variants that were not in strong LD with the conditional variant $\left(\mathrm{r}^{2}<0.9\right)$.

\section{Annotation and protein interactions}

Sequence-derived polymorphisms were extracted for candidate mutation regions from the corresponding VCF files [22]. All variants with a $-\log _{10}(P)$ higher than 8.4 and located within confidence intervals were annotated. To avoid missing important genes, confidence intervals were extended by $100 \mathrm{~kb}$ on each side.
In addition, functional protein-protein interactions (PPI) encoded by candidate genes were investigated, as well as gene ontology (GO) enrichment, using the STRING Genomics 10.0 database of protein-protein interaction (PPI) networks [23]. This database provides (1) known PPI from curated databases or experiments and (2) PPI predicted on the basis of gene neighborhood, gene fusions, gene co-occurrence, text mining in literature, co-expression, or protein homology. A global PPI network was constructed which retained only interactions with a high level of confidence (score $>0.4$ ).

\section{Results}

The results of imputation accuracy at the sequence level for SNPs used in the GWAS analyses (MAF $\geq 2 \%$ ) are in Table 3. Squared correlations between imputed and true genotypes in the validation set reached 76 and $84 \%$, in Montbeliarde and Holstein breeds, respectively. This table also presents the overall results of concordance rate. Figure 1 shows the imputation precision according to MAF in the two breeds.

Among the 13 million tested variants, 71,755 had genome-wide significant effects $\left(-\log _{10}(P) \geq 8.4\right)$ in at least one within-or multi-breed analysis and for at least one milk protein composition trait.

Among these, 29,722, 27,787, and 30,988 were found in within-breed MON, NOR, and HOL analyses, respectively. Some of these variants had significant effects in multiple breeds: 7343 in both MON and NOR, 8055 in NOR and HOL, 8068 in HOL and MON, and 3080 in all three breeds (Table 4; Fig. 2a).

For each trait, the number of significantly associated variants was relatively consistent between breeds. It was lower (from 193 to 2394) for $\alpha_{\mathrm{s} 2}-\mathrm{CN}, \beta-\mathrm{CN}, \alpha_{\mathrm{s} 1}-\mathrm{CN}$, and PC; higher (from 8716 to 19,952 ) for $\beta$-LG, $k$-WP, and 
Table 3 Accuracies of imputations on whole-genome sequences in Holstein (HOL) and Montbéliarde (MON) breeds

\begin{tabular}{lll}
\hline Breed & HOL & MON \\
\hline Number of cows & 168 & 2142 \\
EuroG10k chip version & V1 & V4 \\
Number of markers in the custom part & 721 & 3082 \\
Number of markers after quality control and MAF $\geq 0.02$ & 221 & 1108 \\
$R^{2}(\%)$ & 83.7 & 76.1 \\
Genotypic concordance rate (\%) & 93.7 & 89.7 \\
Allelic concordance rate (\%) & 96.5 & 94.0 \\
\hline
\end{tabular}

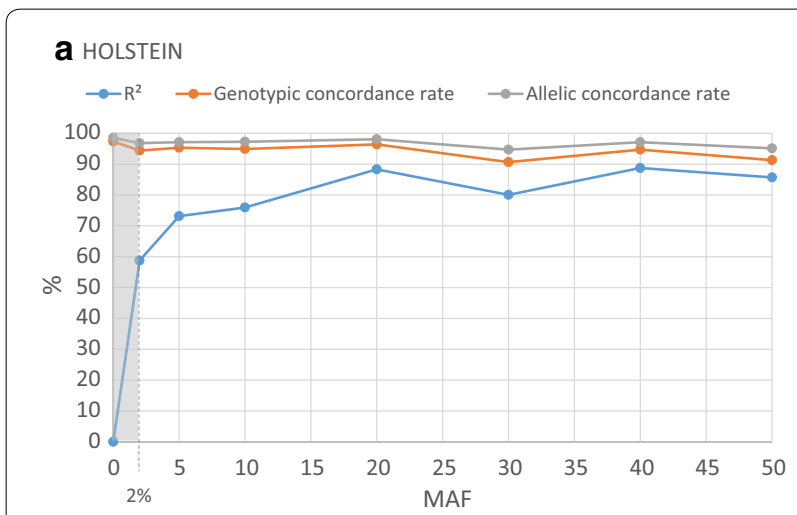

b MONTBELIARDE

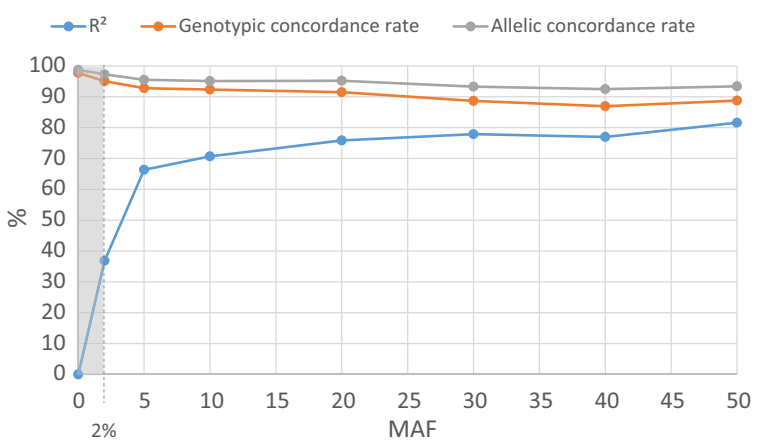

Fig. 1 Precision of imputations at the whole-genome sequence level in a Holstein and $\mathbf{b}$ Montbéliarde breeds, according to MAF. The 2\% limit corresponds to the MAF threshold for markers used in GWAS

$\Sigma$-CN; and intermediate (from 4110 to 8248 ) for $\alpha$-LA and $\mathrm{k}-\mathrm{CN}$. Among these variants, 0 (PC) to 2266 ( $\beta$-LG) were shared among the three breeds. Multi-breed analyses were more powerful, and detected a larger number of distinct variants with significant effects $(34,248)$ than any of the within-breed analyses. However, the number of variants detected per trait was larger in one of the within-breed analyses than in the multi-breed analysis for PC, $\alpha$-LA, $\beta$-LG, $\Sigma$-CN, and $\Sigma$-WP (Table 4), probably because of the long-range within-breed LD.
QTL regions were defined by merging the overlapping QTL regions obtained for the different traits and breeds and by grouping the corresponding significant results. Confidence intervals of these regions were defined as described in the Methods section. Thus, 34 QTL regions with significant effects on one or several milk protein composition traits were identified in within-breed and/ or multi-breed analyses (see Additional file 2: Table S2). Three of these, located on chromosomes 6,11 , and 14, had significant pleiotropic effects on almost all protein composition traits analyzed (see Additional file 3: Table S3), while most (31 QTL) generally affected only one trait (see Additional file 4: Table S4).

The 34 QTL were distributed on 17 of the 29 bovine autosomes, with one to seven QTL per chromosome. Almost all of them (31) were detected in multi-breed analyses while 11,8 , and 11 QTL regions were found in MON, NOR, and HOL within-breed analyses, respectively. Four QTL regions, located on Bos taurus chromosome BTA6 (two regions at 45.8-46.9 Mbp and 85.2-87.4 Mbp), BTA11 (103.3 Mbp), and BTA20 (58.3$58.4 \mathrm{Mbp}$ ), were detected in three breeds. One additional region on BTA29 at about $9.6 \mathrm{Mbp}$ was common to $\mathrm{MON}$ and $\mathrm{HOL}$, and another region on BTA14 at 1.7-1.8 Mbp was common to HOL and NOR (Fig. 2b). The six QTL shared between two or three breeds had the most significant effects, along with one QTL detected only in the NOR breed on BTA2, at $131.8 \mathrm{Mbp}\left(-\log _{10}(P) \geq 20\right.$; $P$ value $<10^{-13}$ after Bonferroni correction).

Multi-breed analyses led to the detection of a larger number of QTL regions than within-breed analyses: 14 of the 31 QTL detected in multi-breed analyses were not found in within-breed analyses. For the 17 QTL regions found in both within-and multi-breed analyses, the $-\log _{10}(P)$ value of the most significant (top) variant was almost always higher in multi-than in within-breed analyses; this was true even for most of the regions that had significant effects in only one within-breed analysis. For these QTL, the mean $-\log _{10}(P)$ value of the most significant (top) variant was 64 in multi-breed analyses versus 49, 46, and 42 in MON, NOR and HOL within-breed analyses, respectively. In addition, the QTL confidence intervals generated by multi-breed analyses contained a smaller number of variants than those produced by within-breed analyses. For the 17 QTL regions, an average of 134 variants (2-374) were found in multi-breed analyses versus 189 (39-335), 287 (61-872), and 308 (9-1236) in MON, NOR, and HOL within-breed analyses, respectively. However, in some QTL regions, specifically those located on BTA2 (131.8 Mbp), 6 (38 Mbp), and 19 (61 Mbp), the number of significant variants was smaller in within-breed analyses than in the multi-breed analysis. 
Table 4 Number of variants with genome-wide significant effects $\left(-\log _{10}(P)>8.4\right)$ for milk composition traits in withinand multi-breed analyses

\begin{tabular}{|c|c|c|c|c|c|}
\hline \multirow[t]{2}{*}{ Trait } & \multicolumn{4}{|c|}{ Within-breed analyses } & \multirow[t]{2}{*}{ Multi-breed analyses } \\
\hline & MON $^{a}$ & $\mathrm{NOR}^{\mathrm{a}}$ & $\mathrm{HOL}^{\mathrm{a}}$ & Shared among three breeds & \\
\hline PC & 1905 & 1201 & 2394 & 0 & 2350 \\
\hline$a-L A$ & 4590 & 6490 & 8248 & 213 & 7224 \\
\hline$\beta-L G$ & 19,952 & 16,048 & 15,517 & 2266 & 18,612 \\
\hline$a_{s 1}-C N$ & 2232 & 708 & 629 & 182 & 2280 \\
\hline$a_{\mathrm{s} 2}-\mathrm{CN}$ & 866 & 193 & 636 & 1 & 1947 \\
\hline$\beta-C N$ & 665 & 734 & 524 & 96 & 1652 \\
\hline $\mathrm{k}-\mathrm{CN}$ & 4110 & 5878 & 6532 & 553 & 7012 \\
\hline$\Sigma$-CN & 13,920 & 8716 & 11,833 & 961 & 12,698 \\
\hline$\Sigma$-WP & 16,583 & 13,126 & 15,327 & 1916 & 16,546 \\
\hline Total number of distinct variants & 29,722 & 27,787 & 30,988 & 3080 & 34,248 \\
\hline
\end{tabular}

a Montbéliarde (MON), Normande (NOR), and Holstein (HOL) cows

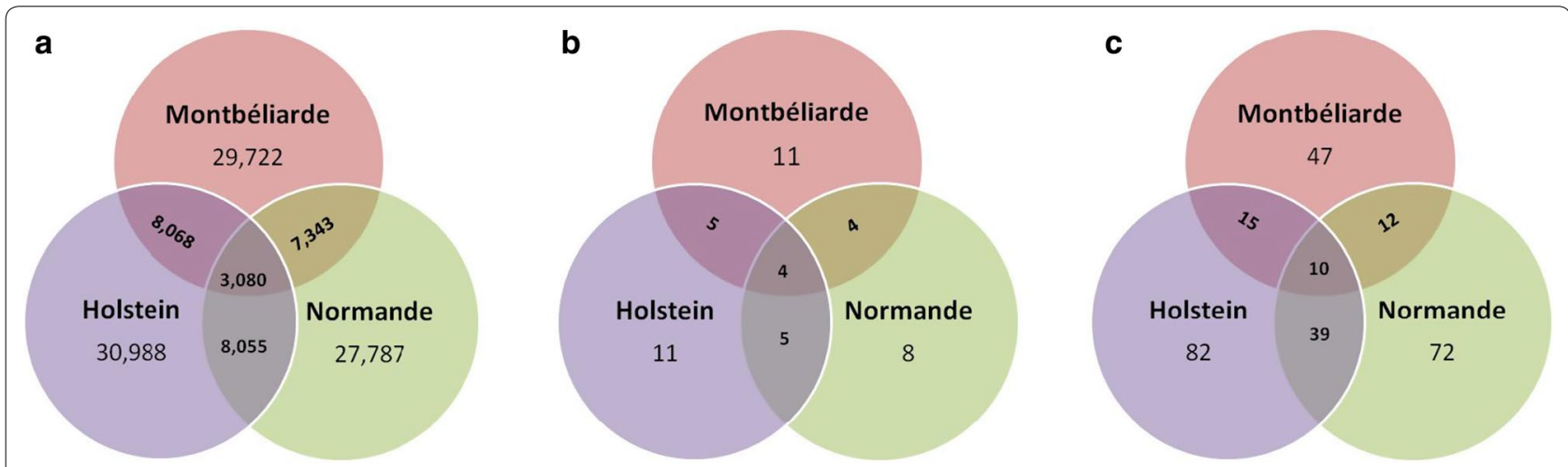

Fig. 2 Number of overlapping a variants with genome-wide significant effects $\left(-\log _{10}(P) \geq 8.4\right), \mathbf{b}$ QTL regions, and c genes containing variants with genome-wide significant effects among Montbéliarde, Normande, and Holstein breeds

Manhattan plots of three of the most significant QTL regions are in Fig. 3 for the three densities of markers (50 K SNP, HD SNP, or sequence). In each of these regions, several peaks are detected with the WGS data, whereas with the $50 \mathrm{~K}$ SNP density and in some cases with the HD SNP density, only one peak was observed.

All variants included within confidence intervals $(+100 \mathrm{~kb}$ on each side) were functionally annotated (Table 5) and (see Additional file 5: Table S5). The percentage of variants that were located within genes ranged from $60.5 \%$ in HOL to $73.4 \%$ in NOR within-breed analyses, and it was intermediate in multi-breed analyses (65.8\%). The vast majority of the genic variants were located within introns and in upstream or downstream regions. A total of $25,82,72$, and 56 missense variants were found in MON, NOR, HOL, and multi-breed analyses, respectively; among these, we detected the previously reported missense mutations in the PAEP $(103,303,475 \mathrm{bp})$ and DGAT1 (1,802,266 bp) genes.
In 29 QTL regions, annotation led to the identification of candidate genes for milk protein composition. In total, 47, 72, and 82 candidate genes were identified in MON, NOR, and HOL within-breed analyses (109 in multi-breed analyses). Some of these were shared across breeds: 12 were found in both MON and NOR, 15 in MON and HOL, 39 in HOL and NOR, among which 10 were common to the three breeds (Fig. 2c). However, within a given region, the top variant was always different among the different breeds. The top variant was located in a gene in 21 of these regions, while in the remaining eight regions, the top variant was intergenic. However, these eight regions contained other variants located within confidence intervals that were annotated in genes, and of these, the most significant one was denoted the top genic variant. Genic variants with the most significant results were located within intron regions for 15 QTL and mainly upstream or downstream regulatory regions for 14 QTL. In total, 22 genes were identified as 


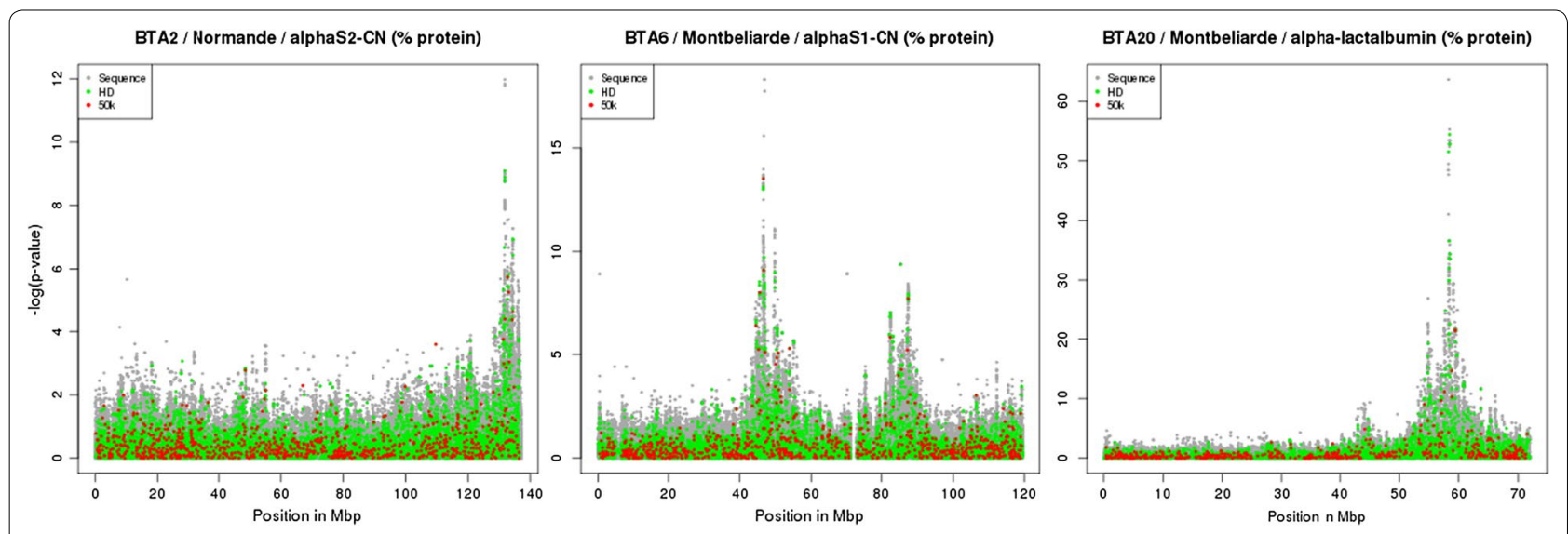

Fig. $3-\log _{10}(P)$ plotted against the position of variants on BTA2, 6, and 20 using three SNP densities: $50 \mathrm{~K}$, HD, and whole-genome sequence SNPs

Table 5 Functional annotations of variants included within confidence intervals $( \pm 100 \mathrm{~kb}$ ) of the 34 QTL in the three within-and multi-breed analyses

\begin{tabular}{lllll}
\hline Functional annotation & \multicolumn{2}{l}{$\begin{array}{l}\text { Within-breed } \\
\text { analyses }\end{array}$} & \multicolumn{3}{l}{ Multi-breed analyses } \\
\cline { 2 - 4 } & MON $^{\mathbf{a}}$ & NOR $^{\mathbf{a}}$ & HOL $^{\mathbf{a}}$ & \\
\hline Intergenic & 1514 & 1465 & 2676 & 1971 \\
Intronic & 1079 & 1804 & 1937 & 1737 \\
3' UTR & 11 & 14 & 69 & 35 \\
5' UTR & 14 & 27 & 16 & 18 \\
Downstream & 710 & 988 & 1276 & 1159 \\
Inframe insertion & 0 & 0 & 1 & 0 \\
Missense & 25 & 82 & 72 & 56 \\
Splice acceptor & 0 & 0 & 3 & 0 \\
Synonymous & 30 & 114 & 118 & 91 \\
Upstream & 509 & 1009 & 612 & 685 \\
\% genic & 61.1 & 73.4 & 60.5 & 65.8 \\
\% genic non intronic & 33.4 & 40.6 & 32.0 & 35.5 \\
\hline
\end{tabular}

${ }^{a}$ Montbéliarde (MON), Normande (NOR), and Holstein (HOL) cows

the best candidates to explain the majority of the variability of milk protein composition in MON, NOR, and $\mathrm{HOL}$ cows. They were located on BTA1 (SLC37A1), BTA2 (ALPL), BTA5 (MGST1), BTA6 (ABCG2, MEPE, PKD2, HERC3, SEPSECS, SEL1L3, DHX15, CSN1S1, CSN2, CSN1S2, and CSN3), BTA11 (PAEP), BTA14 (DGAT1, RECQL4, MROH1, and BOP1), BTA20 (ANKH), BTA27 (AGPAT6), and BTA29 (PICALM).

Protein-protein interactions (PPI), as well as GO enrichment, were investigated for the 22 most plausible candidate genes of our study. Network proteins encoded by these genes had significantly more interactions than expected (10 edges identified; PPI enrichment $P$ value $=3.4 \times 10^{-9}$; Fig. 4 ), while GO terms for
12 biological processes, seven cellular components, and one molecular function were significantly (FDR $<0.05$ ) enriched with two to nine of these genes for milk protein composition (Table 6).

\section{Discussion}

In this paper, we report the results of a whole-genome sequence scan for milk protein composition predicted from MIR spectra. We conducted within-and multibreed analyses using imputed WGS of 7907 cows from three French dairy breeds. This approach led to the detection of 34 distinct regions that affect the protein composition of milk. The use of imputed WGS enabled us to confirm 22 of the 39 QTL that were previously detected from $50 \mathrm{~K} \mathrm{SNP}$ genotypes [8] and to identify 12 novel QTL. In addition to genetic parameter results [4] and QTL detection results with the $50 \mathrm{~K}$ chip [8], these results confirm that MIR predictions are sufficiently accurate for genetic investigations. Repeated test-day records compensated for the moderate MIR prediction accuracy of some proteins.

Seventeen QTL that had been detected with $50 \mathrm{~K}$ SNP genotype data were not found with imputed WGS, possibly because different methods were used in the two studies (linkage disequilibrium and linkage analysis in the $50 \mathrm{~K}$ SNP study versus GWAS in the current imputedWGS study) and also possibly because of the more stringent significance thresholds applied here. For GWAS on WGS data, the very stringent threshold that we used (with Bonferroni correction considering all variants as independent) probably reduced the detection power but minimized the number of false positive QTL.

Instead, the better resolution of the WGS data, combined with the power of the multi-breed GWAS approach, led to the detection of 12 QTL that were not previously found in the $50 \mathrm{~K} \mathrm{SNP}$ study. To evaluate the 


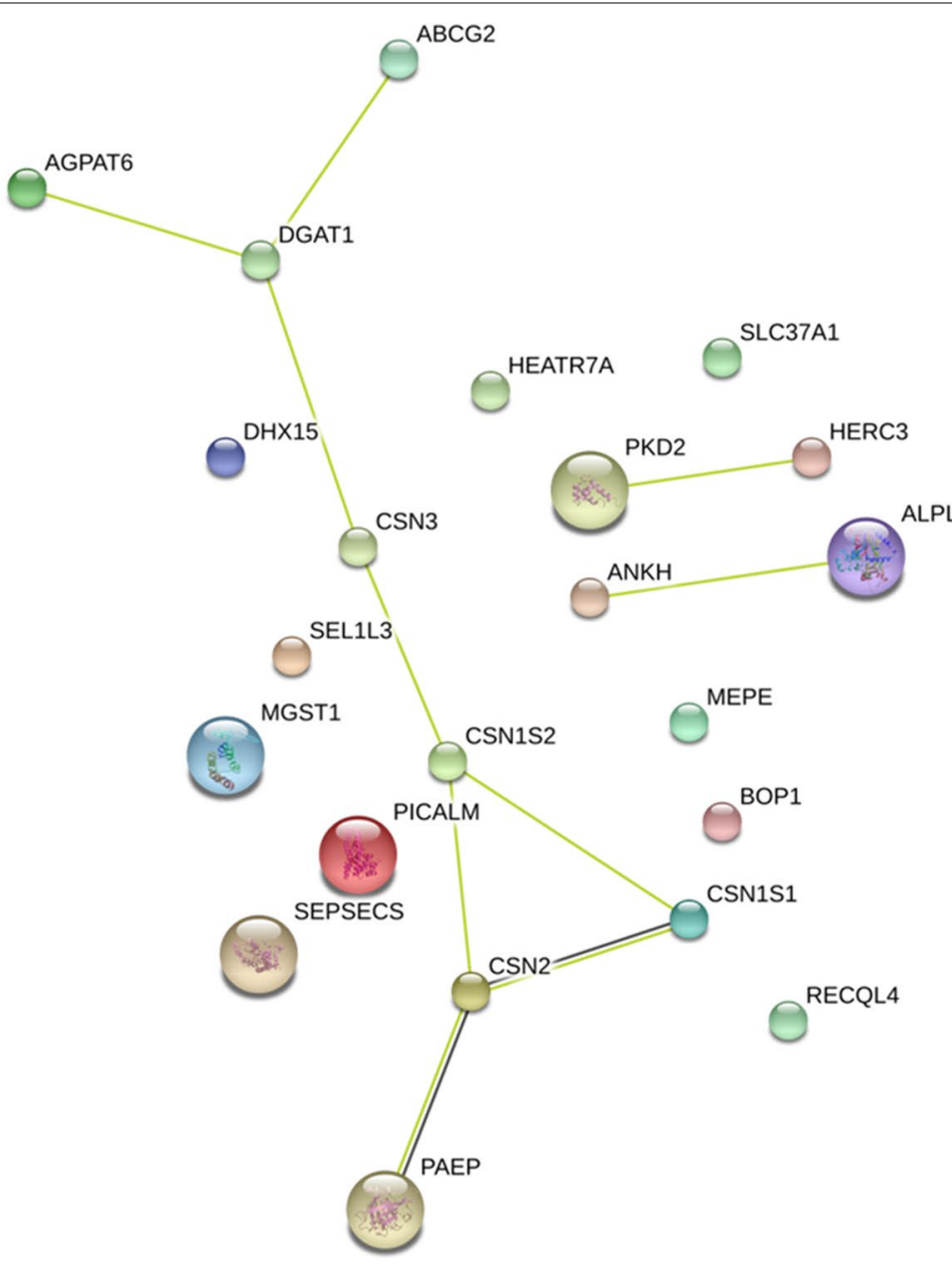

\section{Nodes:}

Network nodes represent proteins

splice isoforms or post-translational modifications are collapsed, i.e. each node represents all the proteins produced by a single, protein-coding gene locus.

Edges:

Edges represent protein-protein associations

associations are meant to be specific and meaningful, i.e. proteins jointly contribute to a shared function; this does not necessarily mean they are physically binding each other.
Node Size

- small nodes:

protein of unknown $3 D$ structure

(3) large nodes:

some $3 D$ structure is known or predicted

Node Color

Known Interactions

C-O from curated databases

C-O experimentally determined
Others

e- - textmining

-O co-expression

e-O protein homology

Fig. 4 Protein network of the 22 most probable candidate genes detected, according to STRING v10.0 action view

impact of marker density on GWAS results, we extracted $50 \mathrm{~K}$ and HD GWAS results from the WGS results. In several genomic regions, for example the regions on BTA2, 6, and 20 (Fig. 3), the increased resolution of the WGS data clearly makes it possible to identify two or more peaks whereas analysis of the $50 \mathrm{~K} \mathrm{SNP}$ data detected only one peak.

Furthermore, the WGS resolution enables the use of a multi-breed approach, which is expected to better estimate the effects of rare variants and to reduce 
Table 6 Gene Ontology (GO) functional enrichment with false discovery rate (FDR) $<0.05$

\begin{tabular}{|c|c|c|c|c|c|}
\hline & Pathway ID & Pathway description & Gene count & FDR & Genes \\
\hline \multirow[t]{12}{*}{ Biological process } & GO.1903494 & Response to dehydroepiandrosterone & 4 & $1.73 e-08$ & CSN1S1, CSN1S2, CSN2, CSN3 \\
\hline & GO.1903496 & Response to 11-deoxycorticosterone & 4 & $1.73 e-08$ & CSN1S1, CSN1S2, CSN2, CSN3 \\
\hline & G0.0032570 & Response to progesterone & 4 & $1.81 \mathrm{e}-07$ & CSN1S1, CSN1S2, CSN2, CSN3 \\
\hline & G0.0097305 & Response to alcohol & 5 & $3.69 e-07$ & ALPL, CSN1S1, CSN1S2, CSN2, CSN3 \\
\hline & G0.0032355 & Response to estradiol & 4 & $2.34 \mathrm{e}-06$ & CSN1S1, CSN1S2, CSN2, CSN3 \\
\hline & GO.1901700 & $\begin{array}{l}\text { Response to oxygen-containing com- } \\
\text { pound }\end{array}$ & 6 & $9.04 \mathrm{e}-05$ & ALPL, CSN1S1, CSN1S2, CSN2, CSN3, PKD2 \\
\hline & G0.0014070 & Response to organic cyclic compound & 5 & 0.000176 & ALPL, CSN1S1, CSN1S2, CSN2, CSN3 \\
\hline & G0.0033993 & Response to lipid & 5 & 0.000181 & ALPL, CSN1S1, CSN1S2, CSN2, CSN3 \\
\hline & G0.0009719 & Response to endogenous stimulus & 5 & 0.00205 & CSN1S1, CSN1S2, CSN2, CSN3, PKD2 \\
\hline & G0.0048732 & Gland development & 3 & 0.0281 & CSN2, CSN3, PKD2 \\
\hline & G0.0060416 & Response to growth hormone & 2 & 0.0281 & CSN1S1, CSN1S2 \\
\hline & G0.0007595 & Lactation & 2 & 0.0298 & CSN2, CSN3 \\
\hline \multirow[t]{7}{*}{ Cellular component } & G0.0005796 & Golgi lumen & 4 & $1.97 e-08$ & CSN1S1, CSN1S2, CSN2, CSN3 \\
\hline & GO.0012505 & Endomembrane system & 8 & 0.00253 & $\begin{array}{l}\text { AGPAT6, CSN1S1, CSN1S2, CSN2, CSN3, DGAT1, } \\
\text { MGST1, PKD2 }\end{array}$ \\
\hline & GO.0005576 & Extracellular region & 7 & 0.0372 & $\begin{array}{l}\text { ALPL, CSN1S1, CSN1S2, CSN2, CSN3, PAEP, } \\
\text { PKD2 }\end{array}$ \\
\hline & G0.0005789 & Endoplasmic reticulum membrane & 4 & 0.0372 & AGPAT6, DGAT1, MGST1, PKD2 \\
\hline & GO.0042175 & $\begin{array}{l}\text { Nuclear outer membrane-endoplasmic } \\
\text { reticulum membrane network }\end{array}$ & 4 & 0.0372 & AGPAT6, DGAT1, MGST1, PKD2 \\
\hline & GO.0044444 & Cytoplasmic part & 9 & 0.0372 & $\begin{array}{l}\text { ABCG2, AGPAT6, CSN1S1, CSN1S2, CSN2, CSN3, } \\
\text { DGAT1, MGST1, PKD2 }\end{array}$ \\
\hline & GO.0044446 & Intracellular organelle part & 9 & 0.0372 & $\begin{array}{l}\text { ABCG2, AGPAT6, CSN1S1, CSN1S2, CSN2, CSN3, } \\
\text { DGAT1, MGST1, PKD2 }\end{array}$ \\
\hline Molecular function & GO.0035375 & Zymogen binding & 2 & 0.0177 & CSN1S2, CSN3 \\
\hline
\end{tabular}

LD between neighboring variants. With the multi-breed analysis, we detected 14 QTL that were not detected in any of our within-breed analyses (see, for example, regions of the MGST1 and AGPAT6 genes described below). For QTL that were detected in both within-and multi-breed analyses, the multi-breed approach provided smaller confidence intervals of the QTL than withinbreed analyses. The three French breeds used in our study are not strongly related. Based on $50 \mathrm{~K} \mathrm{SNP} \mathrm{data,}$ Gautier et al. [24] reported a partitioning of the genetic diversity of cattle into distinct groups of breeds with high geographical consistency. The three breeds were classified into three distinct groups: from Eastern France and Alps for MON, from Northern European for HOL and from the Channel Islands and Northwestern France for NOR. Thus, our results illustrate the extent to which a multi-breed approach can complement and enhance the information gained from within-breed analyses even if breeds pooled in multi-breed analyses have different genetic origins.

In a previous study [25], the imputation from $50 \mathrm{~K}$ to HD SNP densities was found to be very accurate in all three breeds with the number of HD genotypes used here
( $>500)$ in calibration. For the second imputation step, from HD SNPs to WGS, we used the Run 4 reference population of the 1000 Bull Genomes consortium, which contained 1147 bulls, of which 288 were HOL, 28 were MON, and 24 were NOR. Due to the larger number of sequenced HOL bulls compared to the two other breeds, imputation is more accurate with $\mathrm{HOL}$ data than with MON data. In NOR, we anticipate that imputation accuracy is close to that obtained in MON due to similar population structures and similar numbers of whole-genome sequences for major ancestors in both breeds. These results are in agreement with or are better than those already published in cattle. Daetwyler et al. [9] showed that the use of the 1000 Bull Genome multi-breed population (Run 2, 234 bulls) led to a similar imputation accuracy among data obtained from Holstein-Friesian, Fleckvieh, and Jersey cattle (near $80 \%$ of correlation) in spite of differences in the number of bulls in the reference population (129 Holstein-Friesian, 43 Fleckvieh, and 15 Jersey). Among the PhénoFinlait cows genotyped with the $50 \mathrm{~K}$ SNP Beadchip and then imputed to WGS, 1077 MON, $238 \mathrm{NOR}$, and $498 \mathrm{HOL}$ originated from nine MON, five NOR and eight HOL bulls with WGS available 
in the Run 4 reference population, i.e. 36,9 and $22 \%$ of the PhénoFinlait cows, respectively. As expected, imputation accuracy dropped for variants with a low MAF. In order to limit the impact of imputation errors on the GWAS results, variants with a MAF lower than $2 \%$ were discarded from the analyses and almost all the genetic variants proposed as candidate variants in this study have moderate to high MAF.

Combining within-breed, multi-breed, and conditional GWAS analyses with functional annotations appears to be a good strategy for the differentiation of shared and breed-specific QTL. This approach also enables the direct identification of candidate genes with a very small number of candidate variants, or even in some cases, one unique variant which appears to be the best candidate to explain the observed effects.

On average, depending on the breed, between 60 and $73 \%$ of the QTL variants that we detected in the GWAS were located in genes; this is about twice as high as the percentage of genic variants at the whole-genome scale (35\%; [15]). The most significant variants were located in 49 distinct genes, of which 22 were of particular interest, either because they were found in more than one breed or associated with several traits, or because they were previously described as influencing milk composition. These 22 genes, which are located in 11 distinct genomic regions and present significant protein-protein enrichment, are the most plausible candidates to explain a large part of the variation in milk protein composition among MON, NOR, and HOL cows. In four genomic regions (on BTA1, 2, 11, and 27), we identified one unique candidate variant (or a few candidate variants in LD) shared by all three breeds (in the SLC37A1, ALPL, PAEP, and AGPAT6 genes, respectively). In three other genes, we suggest the presence of a breed-specific candidate variant (MGST1 on BTA5 and PICALM on BTA29) or several candidate causative variants (ANKH on BTA20). Finally, four regions, including the $D G A T 1$ region on BTA14 and three regions on BTA6 ( $A B C G 2$ region, a region at about $46 \mathrm{Mbp}$, and the casein gene cluster), were more complex, because they contained several candidate genes, each with several candidate variants. Eight of these candidate genes (SLC37A1, MGST1, CSN1S1, CSN2, CSN1S2, CSN3, PAEP, and $A N K H)$ are known to be overexpressed in the mammary gland compared to other 17 tissues [26] and between two and nine of them are associated with one of the 20 GO terms in our study. The next sections describe these regions in more detail.

\section{SLC37A1 (BTA1) and as 1-CN/ a-LA}

The SLC37A1 (solute carrier family 37, member A1) gene, which encodes a glucose-6-phosphate transporter that is involved in the homeostasis of blood glucose, is highly expressed in the mammary gland [27]. It could be a good candidate gene to explain the effects of the QTL identified on BTA1 on $\alpha \mathrm{s} 1-\mathrm{CN}$ in both MON and multi-breed analyses and on the $\alpha$-LA phenotype in the multi-breed analysis. In total, 138 distinct variants of this gene were located within the confidence intervals of the QTL, of which 133 were intronic, two were synonymous, and three were downstream (see Additional file 6: Figure S1a). For the $\alpha s 1-\mathrm{CN} / \mathrm{MON}$, $\alpha \mathrm{s} 1-\mathrm{CN} / \mathrm{multi}$, and $\alpha-\mathrm{LA} / \mathrm{multi}$ results, the 80,81 , and 74 most significant variants in the peaks, respectively, were in intronic regions of SLC37A1. One downstream variant was detected for $\alpha s 1-\mathrm{CN}$ in the MON analysis, which ranked 104th among the significant variants, while multi-breed analyses revealed three downstream variants that ranked 81st, 87th, and 103rd. All intronic variants that are located at the top of the peaks are in strong LD but only one variant (indel), located at 144,397,274 bp, was common to all three TOP10 lists; it was 1st in the $\alpha \mathrm{s} 1-\mathrm{CN} / \mathrm{MON}$ ranking, 9th in the $\alpha$ s1-CN/multi-breed ranking, and 4th in the $\alpha-\mathrm{LA} /$ multi-breed ranking. The top1 intronic variant detected in the $\alpha$ s1-CN/multi-breeds analysis, at $144,398,814 \mathrm{bp}$, ranked 75th in the $\alpha \mathrm{s} 1-\mathrm{CN} / \mathrm{MON}$ peak and 76th in the $\alpha$-LA/multi-breed peak.

Two previous studies described the effects of SLC37A1 gene variants on milk production traits. In an analysis of HD SNP genotypes, Kemper et al. [27] described six variants that are located between 144.325 and $144.525 \mathrm{Mbp}$ in this region; the variant with the most significant effect was located in an intronic region of the gene (144,414,936 bp). In our study, this variant was included within the confidence interval of the QTL detected by the multi-breed analysis $\left(-\log _{10}(P)=10.2\right)$, but it ranked 101st. Two other intronic variants in strong LD in the SLC37A1 gene, at $144,367,474$ and $144,377,960 \mathrm{bp}$, were previously proposed as the best candidate mutations for changes in phosphorus concentration and milk production traits [28]. However, in our study in spite of relatively high MAF values (from 0.30 to 0.41 depending on the breed), these variants had a $-\log _{10}(P)$ value lower than 6 for all analyzed traits. In another study of targeted QTL regions after imputation to WGS level, the variant with the most significant effects was located at 144,381,564 bp [29]. This variant is close to the candidate variant identified in our analysis, but it can be excluded as the causal variant in our populations since it is monomorphic in the MON, NOR, and HOL individuals analyzed here.

The conditional analyses that we performed included the two best candidate variants as well as the candidate variant described by Kemper et al. [27]. These revealed that including the variant located at $144,398,814 \mathrm{bp}$ in the model completely removed the original signal while with each of the two other variants, a less significant peak 
persisted (see Additional file 6: Figure S1a). This variant, which has contrasting effects on $\alpha \mathrm{s} 1-\mathrm{CN}$ and $\alpha$-LA phenotypes, but with a more marked effect on the former, therefore constitutes the most probable candidate variant for the effects detected in our study.

\section{ALPL (BTA2) and as2-CN}

The QTL identified on BTA2 at $131.8 \mathrm{Mbp}$ had significant effects on several traits ( $\alpha \mathrm{s} 2-\mathrm{CN}, \beta-\mathrm{CN}$, and $\kappa-\mathrm{CN}$ ). In particular, although the $\alpha \mathrm{s} 2-\mathrm{CN}$-associated peaks were detected in all within-and multi-breed analyses, even if in the MON and HOL analyses, the maximal $\log _{10}(P)$ values did not reach the stringent threshold of 8.4 that we applied in this study (7 and 6.9, respectively; see Additional file 6: Figure S1b). In all analyses, the most significant variants were located in intronic regions of the ALPL (alkaline phosphatase) gene, which encodes a member of the alkaline phosphatase family of proteins. The most significant variant differed among the three within-breed analyses: it was located at 131,806,882 bp in NOR, 131,850,456 bp in MON, and 131,808,301 bp in HOL sequences. Instead, the top-ranked variant in the peak detected in the multi-breed GWAS was located at $131,806,882 \mathrm{bp}$. All three single-breed conditional analyses that included each of these variants as fixed effects lacked peaks (see Additional file 6: Figure S1b). These results suggest that all three intronic variants are in strong LD in the three breeds and that the causal mutation could be shared among breeds. Among all the variants at the top of the peaks, the intronic variant at $131,806,882 \mathrm{bp}$ appears to be the most probable candidate variant in the $A L P L$ gene for the observed effects on $\alpha \mathrm{s} 2-\mathrm{CN}$ content; it ranked 1st, 6th, 26th, and 1st in the NOR, MON, HOL, and multi-breed peaks, respectively.

\section{MGST1 (BTA5) and milk protein content (PC)}

One region on BTA5 that contains 63 variants affected PC in the multi-breed analysis. The MON and NOR within-breed analyses revealed no peaks $\left(-\log _{10}(P)<6\right)$, whereas the HOL analysis detected a single peak with a $-\log _{10}(P)=8$, which was close to the significance threshold of 8.4. Only one gene, MGST1 (microsomal glutathione S-transferase 1), was present within the confidence interval obtained in the multi-breed analysis. Fifty-one variants were located in intronic (29), exonic (1 synonymous), $5^{\prime}$-UTR (2), or regulatory (19 in the upstream region) regions of the gene. The variant with the most significant effects was located at 93,950,211 bp in the upstream region and its $-\log _{10}(P)$ value was 9.3 , versus a value of 8.0 for the variants that ranked 2nd (93,950,116 bp and 93,950,288 bp), which were located, respectively, in the $5^{\prime}$-UTR and upstream regions of the gene. The MAF value for these variants was low in the
MON population $(0.006$; $<$ MAF threshold of 0.02$)$ and ranged from 0.08 to 0.12 in NOR, from 0.37 to 0.42 in $\mathrm{HOL}$, and from 0.19 to 0.22 in the multi-breed population. Thus, the fact that peaks were detected only in HOL (close to significance) and multi-breed (significant) analyses could be due to the relatively low MAF for these variants in MON and NOR. The most significant variants in our study are located near a variant that was reported by Raven et al. [29] to be responsible for changes in fat percentage in Holstein cows (at 93,951,731 bp (upstream) and ranked 23rd in our study) and also near variants previously linked to fat yield by Iso-Touru et al. [30] and Van den Berg et al. [31] (93,945,694 and 93,945,738 bp, respectively; both were intronic variants and were not significant here). Conditional analyses including each of the six variants as a fixed effect showed that all variants except those reported by Iso-Touru et al. [30] and Van den Berg et al. [31] explained the effects observed in our study (see Additional file 6: Figure S1c). Thus, the effects observed on fat content by Raven et al. [29] and on protein content in our study could be explained by the same causative variant. Recently, Littlejohn et al. [32] confirmed that MGST1 has causative pleiotropic effects on milk composition (percentage and yield of fat, protein, and lactose). These authors failed to identify causative variants in the gene but they pointed to a cluster of 17 variants that were grouped in a 10-kbp segment of the MGST1 gene $(93,944,937-93,954,751)$. Only one of these 17 variants is located in the confidence interval of the QTL that we detected and this is an intronic variant $(93,949,810 \mathrm{bp})$ that ranked 7 th in the peak in spite of having a higher MAF (0.32) than the most significant variants (MAF $=0.19-0.22$ ). Thus, our study highlights three new candidate mutations in the MGST1 gene, which are located very close to each other, in the $5^{\prime}$-UTR region $(93,950,116 \mathrm{bp})$ or in the upstream region $(93,950,211$ and $93,950,288 \mathrm{bp})$ of the gene.

\section{ABCG2, MEPE, PKD2, and HERC3 (BTA6) and as1-CN}

Several QTL were found on BTA6. The first one, detected in HOL and multi-breed analyses, was located in the 37.6-38.4 Mbp region, which contains the Y581S polymorphism of the $A B C G 2$ gene $(38,027,010 \mathrm{bp})$ that was described by Cohen-Zinder et al. [33] as a causative mutation for changes in milk yield and composition. This missense variant had MAF values of 0.0029 and 0.0018 in $\mathrm{HOL}$ and multi-breed populations, respectively, and therefore did not pass the MAF filter in both analyses. In spite of a low MAF, the Y581S polymorphism had a highly significant effect on the $\alpha s 1-C N$ phenotype in both HOL and multi-breed analyses, with $-\log _{10}(P)$ values of 31 and 21, respectively; these values were higher than those of the top variant in the peaks after filtering 
for MAF (20 and 15, respectively). However, among the sires of the HOL cows, six bulls were previously found to be heterozygous for the QTL detected in this region, but homozygous for this mutation [8]. Thus, we suggest that other mutations could be responsible for the QTL that affects milk protein composition.

In the HOL analysis, nine variants with MAF ranging from 0.022 to 0.041 were located within the confidence interval of the QTL. The most significant variants were located in intronic regions of the $A B C G 2$ gene, at $38,015,146$ and 38,020,110 bp. Other variants, which are located in three other genes, i.e. MEPE (one downstream), PKD2 (one intronic), and HERC3 (two intronic), also had highly significant effects on $\alpha$ s1-CN. Due to the relatively low MAF of the candidate variants located in this region, these results require further analyses, including a larger number of animals and more accurate imputation or direct genotyping.

\section{SEL1L3, SEPSECS, and DHX15 (BTA6) and as1-CN}

In all within-breed and multi-breed analyses, the $\alpha s 1-\mathrm{CN}$ phenotype was affected by another region of BTA6 at 45.8-46.9 Mbp. However, the most likely candidate genes differed among breeds. In MON, the nine variants with the most significant effects were located in intronic regions of the SEL1L3 gene ( $\max$. at 46,874,151 bp). In NOR, the top 116 variants in the peak were intergenic, while the genic variant with the most significant effects was located in an intron of the SEPSECS gene $(46,277,697 \mathrm{bp})$. In $\mathrm{HOL}$, the most significant genic variants $(D H X 15)$ ranked 16th in the peak $(45,639,181$ and $45,640,564 \mathrm{bp})$. Finally, among the top 80 variants detected by the multi-breed analysis, only one was genic, which was located in an intron of the SEL1L3 gene (46,874,514 bp, ranked 3rd in the MON analysis). There is insufficient concordance among these results to propose a single set of candidate variants.

\section{Pleiotropic effects of the casein gene region (BTA6)}

On BTA6, we found a QTL that affected both the overall protein content of milk and the content of all four individual caseins in all three breeds. Variants with the most significant effects were located in an 840-kb interval that contains the $250-\mathrm{kb}$ casein gene cluster $(87,062,878-$ $87,903,002 \mathrm{bp}$ ); other variants with effects on $\alpha$ s $1-\mathrm{CN}$ and $\beta-\mathrm{CN}$ in MON were located at $85.2 \mathrm{Mbp}$. In all withinand multi-breed analyses, the most significant effects were detected for the $\mathrm{k}-\mathrm{CN}$ phenotype, followed by $\alpha \mathrm{s} 1$, $\alpha s 2$, or $\beta-C N$ depending on the breed. In each analysis, the variant with the most significant effects on $\mathrm{k}-\mathrm{CN}$ was located within or in the immediate vicinity of the CSN3 gene, which encodes the $\kappa$ casein: at $87,376,747 \mathrm{bp}$ (upstream) in NOR, 87,392,592 bp (5'-UTR) in MON and multi-breed, and 87,394,293 bp (downstream) in HOL. Each of these variants, as well as the $\mathrm{K}$ casein $\mathrm{A} / \mathrm{B}$ variant $(87,390,576 \mathrm{bp}$, missense), was therefore included as a fixed effect in the conditional analyses. The results were breed-specific: in $\mathrm{MON}$, the $\mathrm{K}-\mathrm{CN}$-associated peak disappeared after fixing the upstream, missense, or $5^{\prime}$-UTR variant; in $\mathrm{HOL}$, the peak disappeared after fixing the upstream, 3'-UTR, or downstream variant; but in NOR, the peak remained with the inclusion in the model of any of the four variants. Thus, none of the four candidate variants succeeded in explaining all the effects observed on $\mathrm{K}-\mathrm{CN}$ in the three breeds.

Instead, the peaks associated with the $\alpha s 2-\mathrm{CN}$ and $\beta-\mathrm{CN}$ phenotypes in NOR and the PC and $\alpha$ s $2-\mathrm{CN}$ phenotypes in MON could be explained by two distinct groups of six SNPs in complete LD, which were respectively located in the CSN2 gene (three downstream and three intronic) and in the upstream region of the $O D A M$ (odontogenic ameloblast-associated) gene (between the CSN1S2 and CSN3 genes).

Finally, the A1/B and A2 variants of CSN2, which ranked 147th and 86th, respectively, for their effects on $\mathrm{PC}$ and $\alpha \mathrm{s} 2-\mathrm{CN}$ in NOR, were responsible for the as2-CN phenotype in NOR but not for any other effect on the other traits or in the other breeds.

These results illustrate the complexity that is inherent with the analysis of the casein gene cluster, which contains the four genes CSN1S1-CSN2-CSN1S2-CSN3 (encoding, respectively, $\alpha s 1, \beta, \alpha s 2$, and $\mathrm{k}$ caseins). The polymorphisms of the amino-acid sequences of caseins are well known, and the effects on milk composition and cheese-making abilities have been well described (reviewed in Grosclaude et al. [34] and Caroli et al. [35]). Nevertheless, the effects of known polymorphisms are not always consistent between studies, likely because variations in the content of individual caseins are caused by several linked polymorphisms in the casein genes. Thus, it is likely that the most significant variants highlighted in our study are those that better explain haplotype effects. A multi-marker approach could facilitate efforts to distinguish the effects of all the causal polymorphisms located in this region.

\section{Pleiotropic effects of the PAEP gene region (BTA11)}

The most significant effects on protein composition were found for variants that are located on BTA11. Contents of each individual protein in milk, with the exception of $\alpha s 2-\mathrm{CN}$, were affected by this region in all three breeds. Effects were most significant for $\beta$-LG and, to a lesser extent, for $\mathrm{k}-\mathrm{CN}$ in all within-and multi-breed analyses. All of the most significant variants were located in or close to the PAEP (progestagen-associated endometrial protein) gene, also named $L G B$ gene, which encodes the 
$\beta$-LG protein. The $\beta$-LG protein variants $A$ and $B$, which are common in most cattle breeds, are associated with different $\beta$-LG levels in milk [34]. They differ by two amino-acid substitutions, caused by two missense mutations at 103,303,475 and 103,304,757 bp [36]. Interestingly, although these two variants had highly significant effects on $\beta$-LG in our study, they did not rank high in the peaks. In the MON and NOR analyses, both mutations were in complete LD and ranked 85th and 213rd, respectively, while in $\mathrm{HOL}$, the two mutations ranked 48th and 109th, respectively (116th and 120th in multibreed analysis). As suggested by Ganai et al. [36], differences in $\beta$-LG content may be caused by different levels of expression of the $\mathrm{A}$ and $\mathrm{B}$ alleles rather than by the direct effect of amino-acid substitutions. Among the top 30 variants in the within-and multi-breed analyses, only one, located at 103,298,431 bp in the upstream region of the PAEP gene, was shared by the four analyses. Moreover, this variant is one of the most significant in each analysis, ranking 6th, 4th, 1st, and 3rd, respectively, in the MON, NOR, HOL, and multi-breed analyses. The inclusion in conditional analyses of one of the causal missense variants or the most probable upstream variant identified in our study led to similar results in MON and HOL but not in NOR (see Additional file 6: Figure S1d). A peak remained in the conditional NOR analysis when missense mutations were fixed, but disappeared with the inclusion of the upstream variant at 103,298,431 bp. Thus, these results indicate that the missense mutations that cause the $\mathrm{A}$ and $\mathrm{B}$ variant protein polymorphisms do not explain all the variation associated with this region. Another variant, which is located in a regulatory region of $P A E P$, is more or less linked to the missense variants depending on the breed and appears to be a good candidate to explain different levels of expression of $\beta$-LG protein variants.

\section{Pleiotropic effects of the DGAT1 gene region (BTA14)}

Very significant effects on different protein composition traits were associated with the region of the DGAT1 gene in NOR and HOL but not in MON. This region affected PC and $\kappa-C N$ in both NOR and HOL; $\alpha s 1-\mathrm{CN}, \beta-\mathrm{CN}$, and $\alpha$-LA only in NOR, and $\alpha$ s2-CN only in HOL. Moreover, individual proteins with the lowest $P$ value were $\mathrm{k}-\mathrm{CN}$ in NOR and $\alpha s 2-\mathrm{CN}$ in HOL. The A allele of the DGAT1 K232A polymorphism, which decreases fat and protein percentages as well as fat yield, and increases milk and protein yields [37], was present at a frequency of $9.4 \%$ in NOR, $15.8 \%$ in HOL, and only $0.6 \%$ in MON. However, our study confirmed that this causative variant was not the most significant for all traits analyzed. It ranked 18th to 72th among variants in the NOR analysis, depending on the trait, and outside the confidence interval for all traits in HOL. These results suggest, first, that not all variations observed in this region are associated with the K232A polymorphism and, second, that other specific causative mutations could explain the effects detected in NOR and HOL.

A large number of genes are annotated in the 1-Mbp region between 1.5 and $2.5 \mathrm{Mbp}$ on BTA14 and, depending on the trait and the breed, between 66 and 494 variants located within the confidence intervals of this QTL are located in 17 to 30 of those genes. Among the top 50 variants for all traits, six were missense variants, of which two were found in NOR (DGAT1 and BOP1) and four in HOL (three in RECQL4 and one in MROH1). In this region, no variant remained significant in the conditional analyses for NOR when the DGAT1 (K232A) or $B O P 1(1,842,678 \mathrm{bp})$ variants were included, and for $\mathrm{HOL}$ when the variants in RECQL4 (one of the three variants in complete LD: 1,617,841, 1,618,978 and 1,619,555 bp) or $M R O H 1$ (1,878,165 bp) were included. In contrast, a less significant peak persisted when the DGAT1 or BOP1 variant was included in the HOL analyses and when the RECQL4 or MROH1 variant was included in the NOR analyses (see Additional file 6: Figure S1e). Among the six missense variants, only the RECQL4 variant at $1,617,841 \mathrm{bp}$ has a predicted deleterious effect, with a SIFT score of zero. Therefore, in addition to the DGAT1 K232A polymorphism previously identified as having effects on milk composition, we report additional candidate missense mutations in BOP1, MROH1, and RECQL4 genes, which could be partly responsible for the effects associated with the centromeric end of BTA14.

\section{ANKH (BTA20) and a-LA}

The GWAS on WGS data detected a QTL with very significant effects on the $\alpha$-LA phenotype in all three within-breed analyses and in the multi-breed analysis; this confirmed our previous report based on a GWAS using $50 \mathrm{~K}$ SNP data [8]. Confidence intervals of the QTL included between one and four genes depending on the within- or multi-breed analysis, and $A N K H$ was the only gene to be highlighted in all four analyses. $A N K H$ encodes an inorganic pyrophosphate transport regulator that helps to prevent the deposition of minerals (calcium and phosphorous) in bones and $\alpha$-LA exhibits a high affinity to metal ions, calcium in particular. In addition, $A N K H$ is highly expressed in mammary tissue in Holstein and Jersey cows [27] and we observed a significant interaction between $A N K H$ and $A L P L$ (candidate gene on BTA2 for effects on $\alpha \mathrm{s} 2-\mathrm{CN}$ ), which suggests a functional link between these two genes (Fig. 4). Thus, ANKH constitutes a good functional candidate for effects on $\alpha$-LA in HOL, MON, and NOR. However, none of the top 50 variants in this QTL were shared among the 
three breeds. In each breed, the most significant variant was located either in intronic regions of the $A N K H$ gene (at 58,422,697 bp in NOR and at 58,450,656 bp in multi-breed analyses) or in an intergenic region. In $\mathrm{MON}$ and $\mathrm{HOL}$, for which the most significant variants were intergenic, $A N K H$ intronic variants ranked 2nd (at 58,446,560 bp) and 13th (at 58,491,204 bp), respectively. After fixing the most significant variant from each within-breed analysis, a peak remained in all conditional analyses (see Additional file 6: Figure S1f), which suggests that several causative mutations in the $A N K H$ gene could be responsible for the variation of the amount of $\alpha$-LA in milk. The most significant variants could be those that are most tightly linked to the causative mutations in each breed, which could explain why they were breed-specific.

\section{AGPAT6 (BTA27) and k-CN}

The multi-breed analysis detected a QTL for $\mathrm{k}-\mathrm{CN}$ content located at about $36.2 \mathrm{Mbp}$ on BTA27, while in withinbreed analyses, peaks were present in MON and NOR but they did not reach significance $\left(-\log _{10}(P)<8.4\right)$, and no peak was observed in HOL (see Additional file 6: Figure S1g). In the multi-breed analysis, the four most significant variants were located in an intergenic region but the variants that ranked 5 th to 17 th were located in the AGPAT6 gene, which was previously described as a functional gene for milk fat content with pleiotropic effects on other milk components, in particular protein content [38]. The five most significant variants in the gene were in complete $\mathrm{LD}$ and located in the upstream region (at $36,209,319,36,211,252,36,211,258$, and $36,211,708 \mathrm{bp}$ ) or in the $5^{\prime}$-UTR region (at $36,212,352 \mathrm{bp}$ ) of the AGPAT6 gene. For the five linked variants, MAF were equal to 0.46 in MON, 0.47 in NOR, and 0.39 in HOL (0.44 in multi-breed population). When the $\mathrm{k}-\mathrm{CN}$ phenotype was conditioned on the effect of any of these mutations, the association signals completely disappeared in the MON, NOR, and multi-breed analyses (see Additional file 6: Figure S1g). The four variants located in the upstream region were previously identified as candidate causal polymorphisms in both Holstein and Fleckvieh cows by Daetwyler et al. [9]. These authors pointed to the polymorphism at 36,211,252 bp as the most plausible causative mutation because it presented a high probability of being within a transcription binding site. In addition, Littlejohn et al. [38] described strong associations between milk composition traits (fat, protein, and lactose) and 10 variants in the AGPAT6 gene. Three of these 10 variants were among the most significant variants in our study, located at 36,209,319, 36,211,708, and 36,212,352 bp. Thus, we identified five putative causative variants in the AGPAT6 gene for milk protein composition; of these, the variant at $36,212,352 \mathrm{bp}$ appears to be the most plausible causative mutation because it is located in the $5^{\prime}$-UTR region of the AGPAT6 gene. However, the lack of a significant effect in the HOL analyses, in spite of the high MAF of the candidate variants, probably reflects additional effects yet to be explained.

\section{PICALM (BTA29) and as1-CN}

The as1-CN phenotype was influenced by a genomic region that is located at about $9.5 \mathrm{Mbp}$ on BTA29. Significant associations were found in MON, HOL, and multibreed analyses, and a peak close to significance was found in NOR $\left(-\log _{10}(P)=7.9\right)$ (see Additional file 6: Figure $\mathrm{S} 1 \mathrm{~h})$. In the MON and $\mathrm{HOL}$ analyses, the most significant variants were intergenic and, likewise, in the multi-breed analysis, all nine variants located within the confidence interval were intergenic. The most significant non-intergenic variants were located in the PICALM gene in MON and HOL. Two intronic variants ranked 11th in the peak detected in MON (9,651,065 and 9,656,439 bp) and one variant that ranked 10th in the HOL analysis, is located in the upstream region of the gene $(9,611,304 \mathrm{bp})$. When conditional GWAS analyses were performed, the inclusion of the intronic variants removed the peak in MON but not in HOL analyses, and conversely, inclusion of the upstream variant removed the peak in HOL but not in MON analyses. In NOR, the peak in question persisted when either intronic or upstream variants were fixed (see Additional file 6: Figure S1h). These results suggest that either the causative variant is different between breeds or that several linked causative variants explain the significant effects observed in this region. The PICALM gene encodes a phosphatidylinositol-binding clathrin assembly protein, and polymorphisms in this gene are associated with the risk of Alzheimer's disease [39] in humans. However, to date, no link was reported between polymorphisms in this gene and bovine milk composition

\section{Conclusions}

Our study provides evidence that a GWAS-based approach applied to fine-scale phenotypes, wholegenome sequences, and multiple breeds provides enough resolution to identify candidate genes and directly pinpoint a limited number of candidate variants in most of these genes. Several variants, some shared among breeds, were identified as plausible candidate mutations for changes in milk protein composition in the three main French dairy cattle breeds. They were located both in genes that had previously been found to affect milk composition (SLC37A1, MGST1, ABCG2, CSN1S1, CSN2, CSN1S2, CSN3, PAEP, DGAT1, AGPAT6) and in genes for which no such relationship was known $(A L P L$, 
$A N K H, P I C A L M)$. In the future, functional analyses will enable the establishment of causative links between these candidate variants and milk protein phenotypes. However, even before such studies are completed, our results offer the opportunity to improve cheese-making properties through the identification of genetic variants associated with changes in milk composition. Direct consequences of these results on practical selection are not obvious and depend on potential premiums on protein composition and on incentives proposed by the milk processing industry. Nevertheless, it would be desirable to favour caseins against whey proteins at least for milk collected for cheese production. Such an option could be implemented by including variants that affect individual proteins in genomic evaluation models.

\section{Additional files}

Additional file 1: Table S1. The 1000 bull genome population (RUN4). (Daetwyler HD, personal communication).

Additional file 2: Table S2. Number of variants included within confidence intervals for each QTL region and trait, regardless of breed.

Additional file 3: Table S3. Description of the pleiotropic QTL regions detected in within-breed (MON, NOR, or HOL) or multi-breed (Multi) analyses.

Additional file 4: Table S4. Description of other significant QTL regions detected in within-breed (MON, NOR, or HOL) or multi-breed (Multi) analyses.

Additional file 5: Table S5. Functional annotations of variants included within confidence intervals ( $\pm 100 \mathrm{~kb}$ ) of the 34 QTL for each trait in the three within-breed Montbéliarde (MON), Normande (NOR), and Holstein $(\mathrm{HOL})$ or in multi-breed analyses.

Additional file 6: Figure S1. $-\log _{10}(P)$ plotted against the position of variants detected by GWAS (in grey) and conditional GWAS (GWAS_COJO; in blue) a On BTA1, b BTA2, c BTA5, d BTA11, e BTA14, f BTA20, g BTA27 and h BTA29

\section{Authors' contributions}

MPS analyzed the data and wrote the manuscript. DB, SF, and $\mathrm{MBr}$ designed the PhénoFinlait project. GM and PM provided reference analyses for milk protein composition. $A G, P C, C H, A B$, and MBo provided support in computing. RL and DR contributed to the estimation of imputation accuracy. All authors read and approved the final manuscript.

\section{Author details}

${ }^{1}$ GABI, INRA, AgroParisTech, Université Paris Saclay, 78350 Jouy-en-Josas, France. ${ }^{2}$ Institut de l'Elevage, 75012 Paris, France. ${ }^{3}$ Allice, 75012 Paris, France.

\section{Availability of data and material}

GWAS results obtained during the current study are available from the corresponding author on reasonable request.

\section{Acknowledgements}

The authors gratefully acknowledge the breeders who participated in the PhénoFinlait program; colleagues from the Institut de l'Elevage and INRA who designed and coordinated the farm sampling program and data collection; the partners of the program, laboratories, manufacturers, and DHI organizations who provided data; Marion Ferrand who developed the MIR prediction equations; and the members of the PhénoFinlait scientific committee who advised and managed this work. The authors would also like to thank the contribution of the 1000 Bull Genomes consortium.

\section{Competing interests}

The authors declare that they have no competing interests.

\section{Funding}

The PhénoFinlait program received financial support from ANR (ANR-08GANI-034 Lactoscan), APIS-GENE, CASDAR, CNIEL, FranceAgriMer, France Génétique Elevage, and the French Ministry of Agriculture. The Cartoseq project was funded by ANR (ANR10-GENM-0018) and APIS-GENE.

\section{Publisher's Note}

Springer Nature remains neutral with regard to jurisdictional claims in published maps and institutional affiliations.

Received: 7 April 2017 Accepted: 30 August 2017

Published online: 18 September 2017

\section{References}

1. Schopen GC, Heck JM, Bovenhuis H, Visker MH, van Valenberg HJ, van Arendonk JA. Genetic parameters for major milk proteins in Dutch Holstein-Friesians. J Dairy Sci. 2009;92:1182-91.

2. Bonfatti V, Cecchinato A, Gallo L, Blasco A, Carnier P. Genetic analysis of detailed milk protein composition and coagulation properties in Simmental cattle. J Dairy Sci. 2011;94:5183-93.

3. Gebreyesus G, Lund MS, Janss L, Poulsen NA, Larsen LB, Bovenhuis H, et al. Short communication: multi-trait estimation of genetic parameters for milk protein composition in the Danish Holstein. J Dairy Sci. 2016;99:2863-6.

4. Sanchez MP, Ferrand M, Gelé M, Pourchet D, Miranda G, Martin P, et al. Short communication: genetic parameters for milk protein composition predicted using mid-infrared spectroscopy in the French Montbéliarde, Normande, and Holstein dairy cattle breeds. J Dairy Sci. 2017;100:6371-5.

5. Wedholm A, Larsen LB, Lindmark-Månsson H, Karlsson AH, Andrén A. Effect of protein composition on the cheese-making properties of milk from individual dairy cows. J Dairy Sci. 2006;89:3296-305.

6. Bonfatti V, Di Martino G, Carnier P. Effectiveness of mid-infrared spectroscopy for the prediction of detailed protein composition and contents of protein genetic variants of individual milk of Simmental cows. J Dairy Sci. 2011;94:5776-85

7. Ferrand M, Miranda G, Guisnel S, Larroque $H$, Leray O, Lahalle F, et al. Determination of protein composition in milk by mid-infrared spectrometry. In Proceedings of the international strategies and new developments in milk analysis VI ICAR Reference Laboratory Network Meeting: 28 May 2012; Cork. 2013;16:41-5.

8. Sanchez MP, Govignon-Gion A, Ferrand M, Gele M, Pourchet D, Amigues Y, et al. Whole-genome scan to detect quantitative trait loci associated with milk protein composition in 3 French dairy cattle breeds. J Dairy Sci. 2016;99:8203-15.

9. Daetwyler HD, Capitan A, Pausch H, Stothard P, Van Binsbergen R, Brøndum RF, et al. Whole-genome sequencing of 234 bulls facilitates mapping of monogenic and complex traits in cattle. Nat Genet. 2014;46:858-67.

10. Raven L, Cocks B, Hayes B. Multibreed genome wide association can improve precision of mapping causative variants underlying milk production in dairy cattle. BMC Genomics. 2014;15:62.

11. Ducrocq V. Genekit, BLUP software. Version June 2011.

12. Sargolzaei M, Chesnais JP, Schenkel FS. A new approach for efficient genotype imputation using information from relatives. BMC Genomics. 2014;15:478.

13. van Binsbergen R, Bink MC, Calus MP, van Eeuwijk FA, Hayes BJ, Hulsegge l, et al. Accuracy of imputation to whole-genome sequence data in Holstein Friesian cattle. Genet Sel Evol. 2014;46:41.

14. Bouwman AC, Veerkamp RF. Consequences of splitting whole-genome sequencing effort over multiple breeds on imputation accuracy. BMC Genet. 2014;15:105 
15. Boussaha M, Michot P, Letaief R, Hoze C, Fritz S, Grohs C, et al. Construction of a large collection of small genome variations in French dairy and beef breeds using whole-genome sequences. Genet Sel Evol. 2016;48:87.

16. Li H, Handsaker B, Wysoker A, Fennell T, Ruan J, Homer N, et al. The sequence alignment/map format and SAMtools. Bioinformatics. 2009;25:2078-9.

17. McLaren W, Pritchard B, Rios D, Chen Y, Flicek P, Cunningham F. Deriving the consequences of genomic variants with the Ensembl API and SNP effect predictor. Bioinformatics. 2010;26:2069-70.

18. Kumar P, Henikoff S, Ng PC. Predicting the effects of coding non-synonymous variants on protein function using the SIFT algorithm. Nat Protoc. 2009;4:1073-82.

19. Yang J, Lee SH, Goddard ME, Visscher PM. GCTA: a tool for genome-wide complex trait analysis. Am J Hum Genet. 2011;88:76-82.

20. Fu WX, Liu Y, Lu X, Niu XY, Ding XD, Liu JF, et al. A genome-wide association study identifies two novel promising candidate genes affecting Escherichia coli F4ab/F4ac susceptibility in swine. PLoS One. 2012;7:e32127.

21. Yang j, Ferreira T, Morris AP, Medland SE, Genetic Investigation of ANthropometric Traits (GIANT) Consortium, DIAbetes Genetics Replication and Meta-analysis (DIAGRAM) Consortium, et al. Conditional and joint multiple-SNP analysis of GWAS summary statistics identifies additional variants influencing complex traits. Nat Genet. 2012;44:369-75.

22. McLaren W, Gil L, Hunt SE, Riat HS, Ritchie GR, Thormann A, et al. The Ensembl variant effect predictor. Genome Biol. 2016;17:122.

23. Szklarczyk D, Franceschini A, Wyder S, Forslund K, Heller D, Huerta-Cepas J, et al. STRING v10: protein-protein interaction networks, integrated over the tree of life. Nucl Acids Res. 2015;43:D447-52.

24. Gautier M, Laloe D, Moazami-Goudarzi K. Insights into the genetic history of French cattle from dense SNP data on 47 worldwide breeds. PLoS One. 2010;5:e13038

25. Hoze C, Fouilloux MN, Venot E, Guillaume F, Dassonneville R, Fritz S, et al. High-density marker imputation accuracy in sixteen French cattle breeds. Genet Sel Evol. 2013;45:33.

26. Chamberlain AJ, Vander Jagt CJ, Hayes BJ, Khansefid M, Marett LC, Millen CA, et al. Extensive variation between tissues in allele specific expression in an outbred mammal. BMC Genomics. 2015;16:993.

27. Kemper KE, Reich CM, Bowman PJ, vander Jagt CJ, Chamberlain AJ, Mason BA, et al. Improved precision of QTL mapping using a nonlinear Bayesian method in a multi-breed population leads to greater accuracy of across-breed genomic predictions. Genet Sel Evol. 2015;47:29.
28. Kemper KE, Littlejohn MD, Lopdell T, Hayes BJ, Bennett LE, Williams RP, et al. Leveraging genetically simple traits to identify small-effect variants for complex phenotypes. BMC Genomics. 2016;17:858.

29. Raven LA, Cocks BG, Kemper KE, Chamberlain AJ, Vander Jagt CJ, Goddard ME, et al. Targeted imputation of sequence variants and gene expression profiling identifies twelve candidate genes associated with lactation volume, composition and calving interval in dairy cattle. Mamm Genome. 2016;27:81-97.

30. Iso-Touru T, Sahana G, Guldbrandtsen B, Lund MS, Vilkki J. Genome-wide association analysis of milk yield traits in Nordic red cattle using imputed whole genome sequence variants. BMC Genet. 2016;17:55.

31. van den Berg I, Boichard D, Lund MS. Comparing power and precision of within-breed and multibreed genome-wide association studies of production traits using whole-genome sequence data for 5 French and Danish dairy cattle breeds. J Dairy Sci. 2016;99:8932-45.

32. Littlejohn MD, Tiplady K, Fink TA, Lehnert K, Lopdell T, Johnson T, et al. Sequence-based association analysis reveals an MGST1 EQTL with pleiotropic effects on bovine milk composition. Sci Rep. 2016;6:25376.

33. Cohen-Zinder M, Seroussi E, Larkin DM, Loor JJ, Everts-van der Wind A, Lee $\mathrm{JH}$, et al. Identification of a missense mutation in the bovine $A B C G 2$ gene with a major effect on the QTL on chromosome 6 affecting milk yield and composition in Holstein cattle. Genome Res. 2005;15:936-44.

34. Grosclaude F. Le polymorphisme génétique des principales lactoprotéines bovines. INRA Prod Anim. 1988;1:5-17.

35. Caroli AM, Chessa S, Erhardt GJ. Invited review: milk protein polymorphisms in cattle: effect on animal breeding and human nutrition. J Dairy Sci. 2009;92:5335-52.

36. Ganai NA, Bovenhuis H, van Arendonk JA, Visker MH. Novel polymorphisms in the bovine beta-lactoglobulin gene and their effects on betalactoglobulin protein concentration in milk. Anim Genet. 2009;40:127-33.

37. Grisart B, Coppieters W, Farnir F, Karim L, Ford C, Berzi P, et al. Positional candidate cloning of a QTL in dairy cattle: identification of a missense mutation in the bovine DGAT1 gene with major effect on milk yield and composition. Genome Res. 2002;12:222-31.

38. Littlejohn MD, Tiplady K, Lopdell T, Law TA, Scott A, Harland C, et al. Expression variants of the lipogenic AGPAT6 gene affect diverse milk composition phenotypes in Bos taurus. PLoS One. 2014;9:e85757.

39. Harold D, Abraham R, Hollingworth P, Sims R, Gerrish A, Hamshere ML, et al. Genome-wide association study identifies variants at CLU and PICALM associated with Alzheimer's disease. Nat Genet. 2009;41:1088-93.

\section{Submit your next manuscript to BioMed Central and we will help you at every step:}

- We accept pre-submission inquiries

- Our selector tool helps you to find the most relevant journal

- We provide round the clock customer support

- Convenient online submission

- Thorough peer review

- Inclusion in PubMed and all major indexing services

- Maximum visibility for your research

Submit your manuscript at www.biomedcentral.com/submit
() BioMed Central 